\title{
Evaluation of High-Resolution Digital Images for the Landscape Characterization of Colonia Settlements
}

By Richard D. Sanchez

Open-File Report 99-403 


\title{
EVALUATION OF HIGH-RESOLUTION DIGITAL IMAGES FOR THE LANDSCAPE CHARACTERIZATION OF COLONIA SETTLEMENTS
}

\author{
Richard D. Sanchez \\ U.S. Geological Survey \\ 521 National Center \\ Reston, VA 20192
}

\begin{abstract}
Colonia settlements, commonly described as rural unincorporated clusters of generally substandard houses, are scattered widely along the southern border of the United States. These settlements, which have proliferated without constraint largely because of the absence of effective controls on rural county land use, often lack access to essential services, such as public water, gas, electricity, telephone, and sewage disposal. A challenging problem in the southwestern border States is how to improve the living conditions of people residing in these settlements. Information about the infrastructure and geographic distribution of colonias will assist the Department of Housing and Urban Development (HUD) in making important decisions on funding grants and assistance programs for meeting the needs of these economically depressed areas. Consequently, the HUD Office of Research, Evaluation, and Monitoring, Washington, D.C., joined with the U.S. Geological Survey (USGS), Reston, Va., to evaluate the potential of forthcoming commercial high-resolution satellite images for the landscape characterization of colonia settlements.
\end{abstract}

Because the Government has high-resolution space sensor systems and commercial ones are planned, satellite images may offer a quick and effective way to gather information about economically depressed areas in the United States. Meanwhile, the USGS and HUD are investigating the applicability of high-resolution digital color images to identify and interpret colonia landscape characteristics. By creating simulated high-resolution 1-m digital color images derived from aerial cameras, this study examines the potential of future spaceborne orbital systems. Applying visual and automated interpretation techniques to high-resolution digital color images can distinguish between contemporary subdivisions with public utilities and colonias without utility structures. The research application of remote sensing, global positioning systems, and geographic information systems in this study yields important information on the usefulness and limits of forthcoming high-resolution spaceborne systems. The anticipated supply of commercially produced 1 - to $4-\mathrm{m}$ resolution satellite data will increase the information available to Federal agency users, but where much finer detail is needed, quality source data will have to come from commercial low-altitude aerial photographs or Government high-resolution satellite images. HUD will need these higher resolution sources to succeed in gathering accurate information about colonia settlements through remote sensing.

Any use of trade, product, or firm names is for descriptive purposes only and does not imply endorsement by the U.S. Government. 


\section{INTRODUCTION}

Over the years, large quantities of satellite data available to the public have not been fully utilized because of a combination of limited markets for low-resolution data, national security restriction of high-resolution data, and lack of application awareness. With the national security restriction of high-resolution data reduced to $1 \mathrm{~m}$ (McDonald, 1995) and the advent of government and commercial high-resolution satellite systems, satellite images may become more useful in largescale geographic information system (GIS) development and maintenance (Seitz, 1995). In December 1998, Space Imaging, Inc., plans to launch a multisensor satellite with ground sample distances (GSD) of $1 \mathrm{~m}$ panchromatic and $4 \mathrm{~m}$ multispectral and an overflight repeat every 3 days. If all planned polar orbital space sensor systems are successfully launched by the year 2004, more than 20 satellites will be providing Earth resource data at GSD's of $1 \mathrm{~m}$ to $30 \mathrm{~m}$ in multispectral bands (Jensen, 1995). Several of these orbital space sensor systems can provide the requirements for large-scale image mapping from space. ${ }^{1}$ Meanwhile, roughly simulated 1-m satellite color images generated from aerial photographs can be used to examine the value of future optimal data when they become available.

Colonia settlements, rural unincorporated clusters of generally substandard houses scattered widely along the southern border of the United States, often lack access to essential services such as public water, gas, electricity, telephone, and sewage disposal. According to the Texas Water Development Board, in 1996 an estimated 340,000 residents lived in 1,436 colonias situated in the State of Texas (Lyndon B. Johnson School of Public Affairs, 1996). Also, 32,000 people live in 35 colonias in Dona Ana County, New Mexico (Sullivan, 1994). These settlements are often located in isolated rural areas and require labor intensive and time consuming fieldwork to accurately detect and quantify (fig. 1). Information about living conditions and location of colonias can assist the Department of Housing and Urban Development (HUD) in making important decisions on funding grants and assistance programs for addressing infrastructure needs. In 1997, the HUD Office of Research, Evaluation, \& Monitoring, Washington, D.C., joined with the U.S. Geological Survey (USGS), Reston, Va., in a pilot study to determine the feasibility of using remote sensing for gathering information on the landscape characteristics of colonia settlements.

\section{Purpose of Study}

The primary goal of this project is to evaluate the usefulness and limitations of $1-\mathrm{m}$ GSD digital color images for detecting the landscape characteristics of colonia settlements. A second goal is to examine the usability of archived satellite data for measuring the changes and growth patterns in these settlements. The selection of public utility structures as the focus of landscape

1 "... reliable identification of cultural features, such as roads, railroads, and buildings that are normally shown on line maps at any scale, requires a ground resolution of 2 - to $3-\mathrm{m} / \mathrm{line}$ pair, or better than a 1 - to $2-\mathrm{m} / \mathrm{pixel}$. If the sensor used for image mapping does not provide this level of resolution, cultural features will not be adequately represented unless they are derived from other source material." (Frederick J. Doyle, 1984) 
characteristics in this study is based on the premise that landscape characteristics of colonia settlements are strongly indicated in part by the absence or scarcity of utility infrastructure, for example, waste, sewer, gas, and electricity.

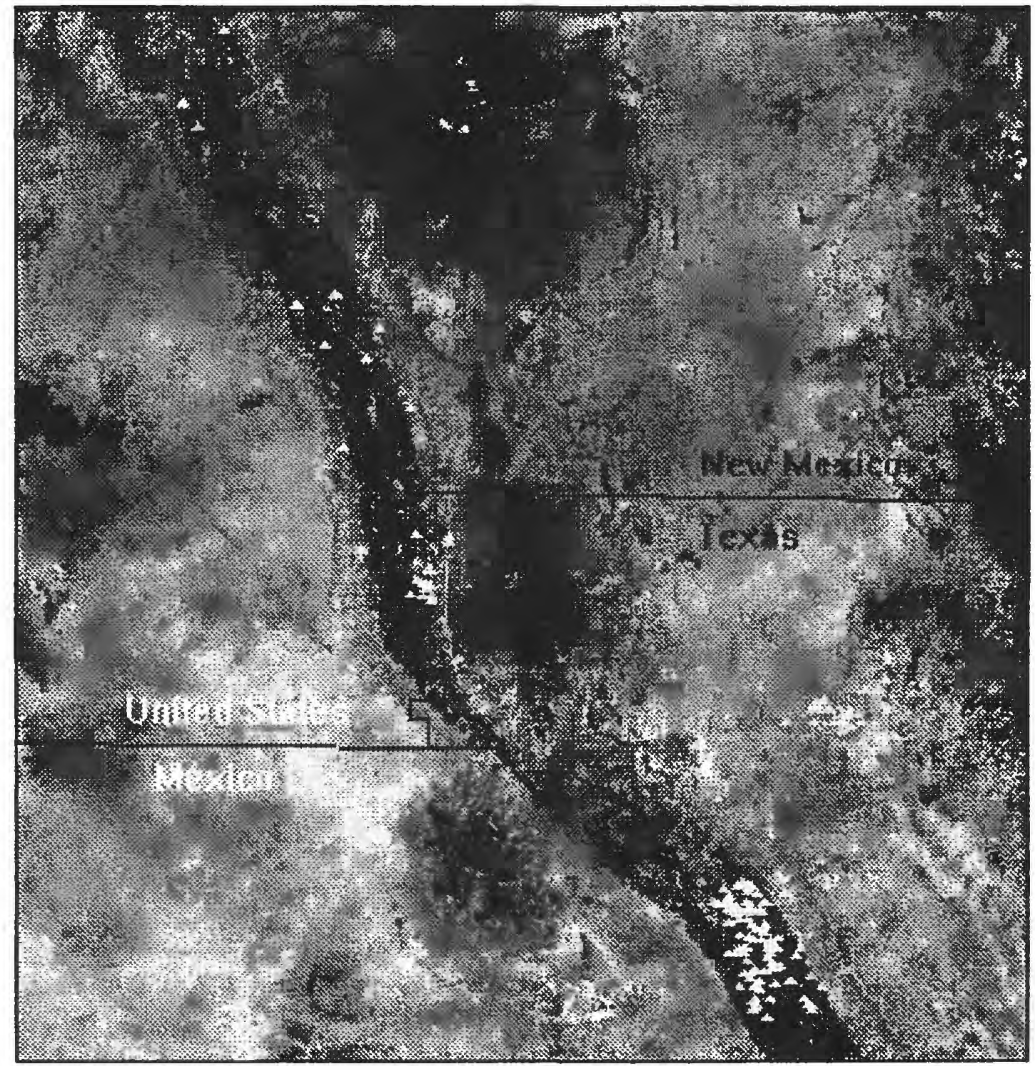

Figure 1. Distribution of colonias settlements (triangles) along the U.S. side of the border.

\section{The Project Area and Source Data}

The project area is located between the rural-urban fringes of the standard metropolitan statistical areas of Las Cruces, N. Mex., and El Paso, Texas. Among the 33 designated colonia settlements in Doña Ana County, Vado IV and La Union were presented by the County Planning Office as sites for the study. The colonia settlement of Vado IV was chosen for the study because it more closely follows the Federal definition of a colonia. That of "a rural unincorporated subdivision in the United States near the Mexican border that lacks either a potable water supply, an adequate waste water system, adequate roads or drainage systems, or safe and sanitary housing" (Albuquerque Journal, 1996). 
According to Holz and Davies (1992), colonias develop on plots of rural land, generally 10-20 acres in size, but sometimes as small as 5 acres or as large as 400 acres. The 275 -acre settlement of Vado IV was developed in the 1980's on three tracts of mostly barren land located off the U.S. Interstate 10 highway outside the corporate limits of Las Cruces and El Paso (fig. 2). Buildings in Vado IV vary in structural appearance, they contain a wide array of architectual designs, ranging from ramshackle shacks of differing sizes and materials to mobile homes, discarded buses, and houses of frame and brick construction. Outhouse privies are common, as well as piles of trash and building materials. Dismembered vehicles and rotting tires lie scattered throughout the settlement.

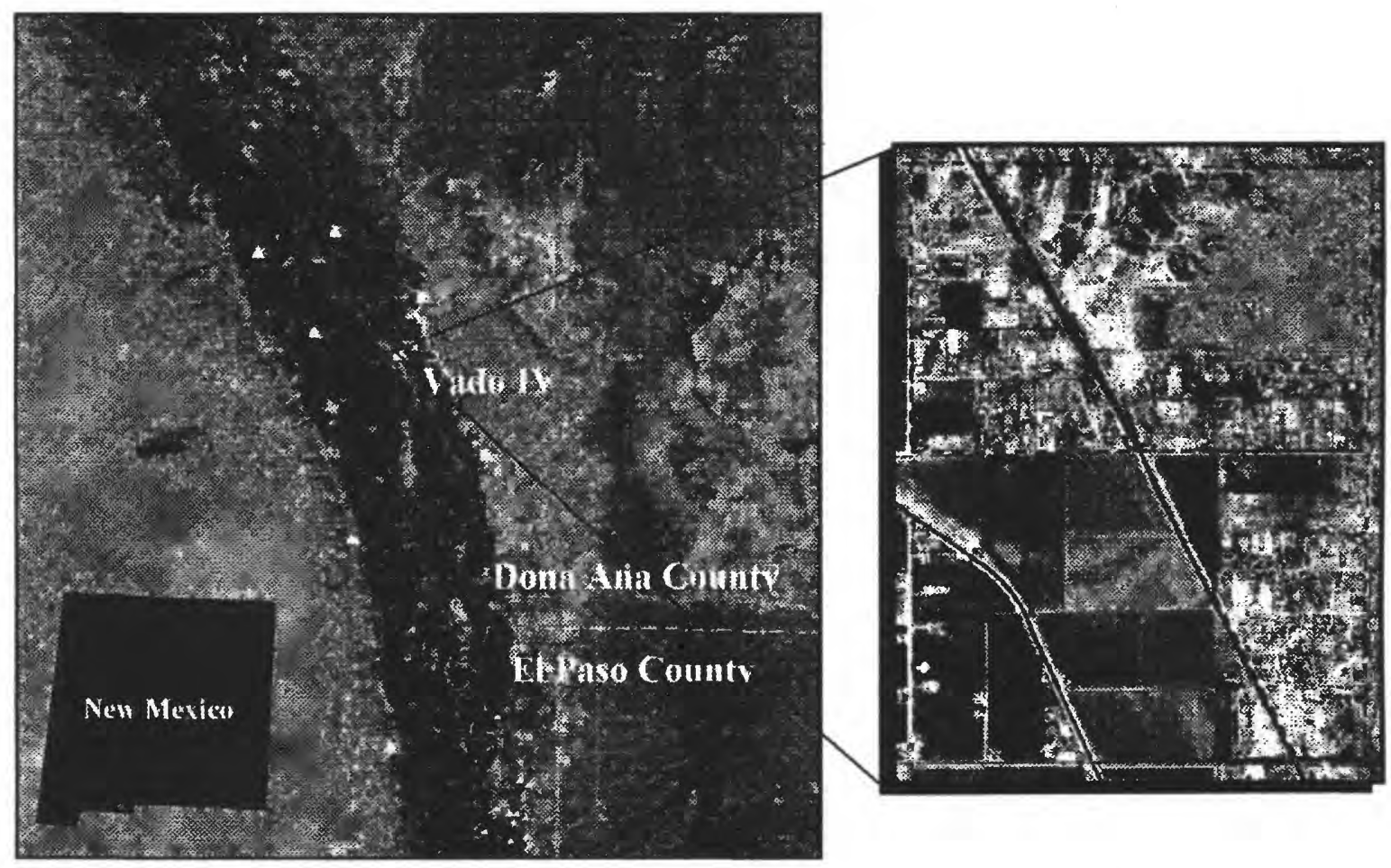

Figure 2. Location of Vado IV (inset of New Mexico shows project area) .

Physically, the project area is located within the Mesilla Basin, the southernmost of a series of basins along the Rio Grande in New Mexico. The basin is bounded by uplifted blocks of bedrock or by relatively impermeable volcanic rocks and is filled with alluvial sediment from the surrounding mountains and fluvial sediment carried by an ancestral Rio Grande (Frenzel and Kaehler, 1990).

The natural vegetation within this Chihuahuan desert climate region with its low precipitation of approximately 8.6 inches annual rainfall is limited to shrubby plants, such as creosote bush, yucca, agave, and sotol. Mesquite, cottonwood, and salt cedar can be found along the Rio Grande and irrigation canals, as well as other types of vegetation, such as alfalfa, cotton, fruit, and nut trees, which were introduced by early settlers. 
The color-infrared (CIR) aerial photographs acquired for this project were collected under the USGS National Aerial Photography Program (NAPP) on March 3, 1996, at a flying height of $6,096 \mathrm{~m}(20,000 \mathrm{ft})$ above mean terrain with a photographic scale of 1:40,000. The CIR 240- by 240-mm (9- by 9-in) film positive was digitally scanned with an aperture of 20 microns yielding digital three-band image about 1-m GSD of approximately 432 megabytes. Also acquired were archived USGS digital orthophoto quadrangle (DOQ), digital elevation model (DEM) and NAPP black-and-white film negatives taken on February 5, 1991. NAPP aerial photographs are customarily collected in black and white using a $152.4-\mathrm{mm}$ (6-in) focal length camera at an altitude of $6,096 \mathrm{~m}(20,000 \mathrm{ft})$. The resultant 240 - by $240-\mathrm{mm}$ film negative is scanned with an aperture of 25 microns, yielding a 1-m GSD digital one-band image of approximately 92 megabytes. The satellite data acquired for this project were collected by Landsat 1 Multispectral scanner (MSS) on October 20,1974, Landsat 4 thematic mapper (TM) on October 28, 1984, and Landsat 5 TM on October 29, 1996, under clear atmospheric conditions (Landsat MSS, Path 35, Row 37, and Landsat TM scenes, Path 33, Row 38). In this study, the data from the thermal band (TM band 6) with a GSD of about $120 \mathrm{~m}$ were not used. The project was also scheduled to evaluate data from the Space Imaging, Inc., satellite (1-m panchromatic, 4-m MSS) for validation of the simulated data results. However, the delays in the launch meant that this task was not possible within the timeframe of the study.

Preexisting spatial base data acquired for this study consist of USGS 1991 digital line graphs (DLG), 1982-84 geographic information retrieval analysis system (GIRAS) land use and land cover data, and 1991 AutoCAD parcel database from the Dona Ana County Planning Office. The USGS DLG data are digital representations of topographic and planimetric map features collected and updated in 1993 using the February 5, 1991, NAPP aerial photographs.

Map materials include USGS 1:24,000-scale 7.5- by 7.5-minute topographic maps of La Mesa, $\mathrm{N}$. Mex., La Union, N. Mex., and Canutillo, Texas/N. Mex. These USGS original topographic quadrangles were compiled or photorevised during the 1954-1974 period using a map projection and grid of the Universal Transverse Mercator (UTM), zone 13, with 1,000-m grid spacing, North American Datum (NAD) 27, and Clarke 1866 Spheroid.

\section{METHODOLOGY}

Public utility structures are the landscape feature characteristics on which this study will focus. A flow chart in figure 3 shows the process applied in this investigation. The methodology consists of the integration and analysis of 1-m digital images and geographic positioning system (GPS) based collected data. A second part of this study examines multidate Landsat MSS and TM sensor data for colonia growth trends and analysis.

To investigate the relationships between landscape characteristics of a colonia settlement and their interpretability in $1-\mathrm{m}$ digital color imagery, we used the following approach. First a typical utility 
network was identified from a nearby subdivision (herein referred to as Oneida) to develop as the base reference. This base reference served as a template to measure the interpretability and

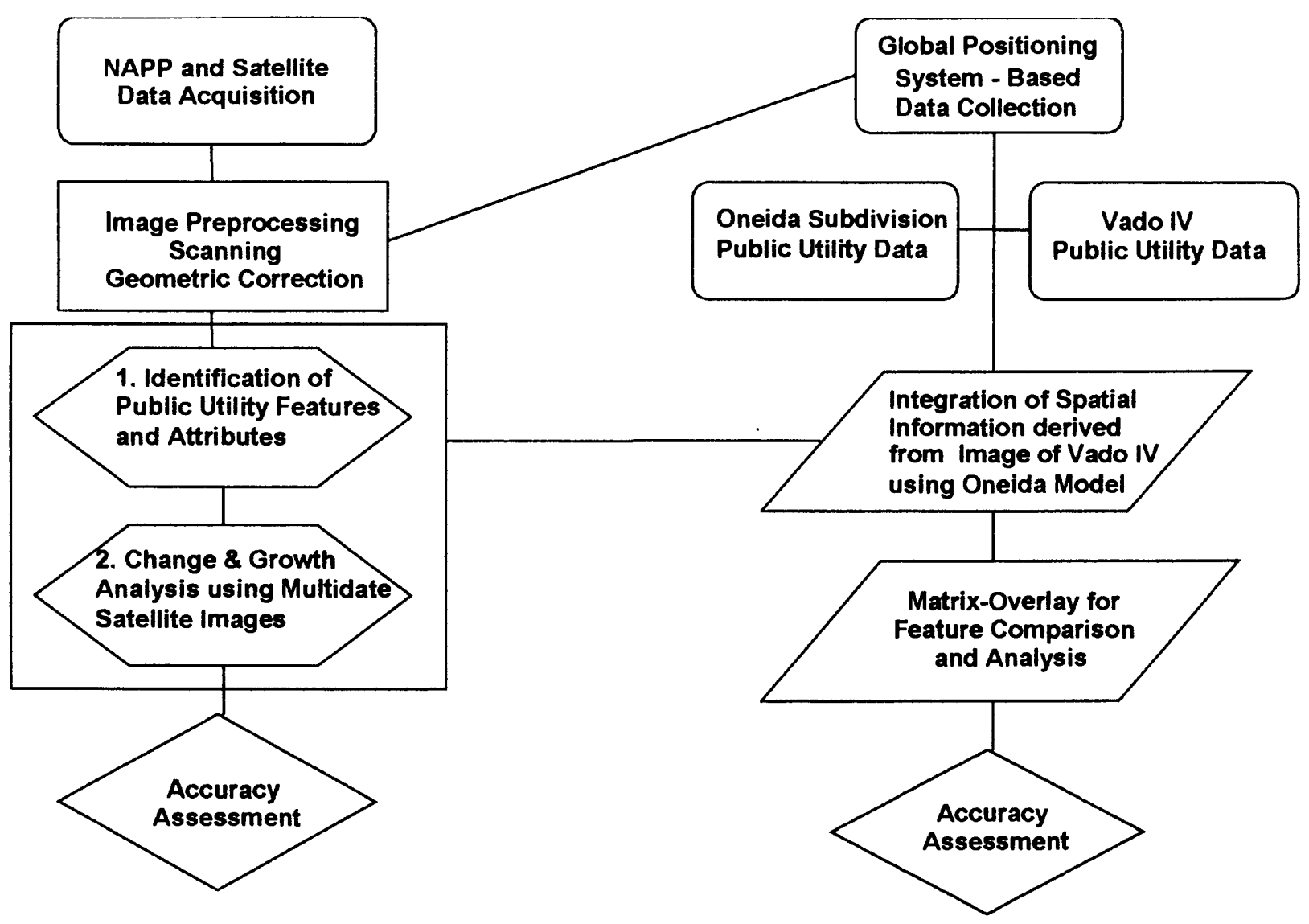

Figure 3. Flow process followed in this study.

information content of the 1-m digital imagery. The multilevel land use and land cover classification of the USGS system (Anderson et al., 1976) was adapted for use by modifying the Transportation, Communication and Utility categories to meet the needs of this investigation (table 1). Field visits to the project site were made in the summer of 1997 and 1998. A geocoded infrastructure GIS was produced of Oneida and Vado IV (using GPS-based collected data). Very little detailed, accurate geographic references for utility structures exist for Vado IV in the form of published or unpublished water, gas, wastewater, and stormwater block maps. County maps, although incomplete, were available of parcel lines, roads (no curb lines), and the water system.

\section{Infrastructure GPS-Based Reference Development}

The pre-onsite field procedure consisted of an inventory, collection, and evaluation of existing base data, followed by transforming useable data for export in a GIS compatible format, and 
setting up the data dictionary and database tables (table 1). Important to the field strategy were planning data-logging routes in advance and defining function keys to capture feature attributes. Identifying National Geodetic Survey (NGS) High Accuracy Reference Network (HARN) locations in the vicinity of the project site proved invaluable for checking the accuracy of GPSdetermined positions at the beginning and end of the day (Sanchez and Hothem, 1998). A mission checklist was used to maximize time efficiency in the field.

Table 1. Utility GIS classification scheme

\begin{tabular}{|llll|}
\hline Level I & Level II & Level II & Level IV \\
\hline 1 Built-up & 14 Transport., & 141 Roads & 141 Dirt/Graded \\
Land & Comm., & & 1412 Dirt/Ungraded \\
& \& Utilities & & 1413 Gravel \\
& & 1414 Paved \\
& & \\
& 147 Utilities & 1471 Catch Basin \\
& & 1472 Electric Vault \\
& & 1473 Fire Hydrant \\
& & 1474 Gas Valve \\
& & 1475 Light (private) \\
& & 1476 Light (street) \\
& & 1477 Manhole (electric) \\
& & 1478 Manhole (gas) \\
& & 1479 Manhole (storm sewer) \\
& & 1480 Manhole (wastewater) \\
& & 1481 Manhole (telephone) \\
& & 1482 Pole (telegraph) \\
& & 1483 Pole (utility) \\
& & 1484 Water Valve \\
& &
\end{tabular}

In the summer of 1997, the field team established a network of well-distributed, image-identified ground control points by real time differential GPS (RT-DGPS) using a Trimble Model 4000 SSE GPS receiver and OMNISTAR 6300A range-correction broadcast service. Both instruments were later replaced in the project by OMNIST AR Model 3000LR12--an integrated RT-DGPS system for GPS observations and reception of broadcasted range correction. The OMNISTAR Model 3000LR12 was cabled to a Micron laptop PC installed with GeoLink GPS/GIS mapping software. Augmenting the RT-DGPS capability was the application of the precise positioning service for point positions determined by autonomous methods with the Rockwell Precise Lightweight GPS + 96 Receiver (PLGR). The external antenna of the GPS receiver was magnetic-mounted on a field pack pole or on the roof of the vehicle. The GPS receiver and GeoLink interface allowed the laptop operator to display the digital image backdrop while recording an average position or logging the footpath or path of the vehicle continuously. The positional data referenced to NAD 83 were transmitted from the GPS receiver to GeoLink by 
NMEA 0183 protocol. The GeoLink export program translated the captured data from its native storage format to ARC SHAPE, the target GIS file format.

The RT-DGPS system used in 1997 and 1998 produced differentially determined positions in realtime with horizontal accuracy at the sub-50-cm level and vertical accuracy at sub-70-cm level. The OMNISTAR service provides GPS range corrections collected at 11 widely spaced ground reference stations and transmitted to the user through a geostationary satellite communication link. The high quality range corrections provided by the OMNISTAR broadcast service are fully exploited by the internal 12-channel GPS engine of the OMNISTAR 3000LR12.

To know the precise grid coordinate of any point in the Oneida subdivision and Vado IV colonia settlement, the team performed registration in the field by locating 25 DGPS-collected ground control points within each of the 1996 scanned aerial photographs and correlating their horizontal position to corresponding geographic coordinates. These points were then used in a least-square regression analysis to derive a first-order polynomial transformation of the three band image with less than a 1-pixel root-mean-square error. Following the registration and nearest neighbor resampling at an output pixel size of 1 by $1 \mathrm{~m}$, we used a high pass box filter to enhance higher spatial frequency components of the image. Because the study area is in a relatively flat area and mapped at a large scale, neither correction for terrain displacement nor orthorectification was deemed necessary for this study.

The GPS receiver and GeoLink field mapping software were used to collect utility structures and attributes. Most of the road data were collected with the GPS receiver's external antenna magnetic-mounted to the roof of the car, which was driven at speeds ranging from 5 to 35 $\mathrm{mph}$. The GeoLink interface with the GPS receiver allowed the operator to display the digital image and track the path of the vehicle. Because there were no heavy tree canopies, tall buildings, or other line-of-sight obstructions in the project area, the external antenna required less than 5 seconds to obtain a fix on the satellites. Once the field team obtained the fix on the satellites, tracking began at 1 -second intervals. Stops were made to identify, collect attributes, and photograph features. Information about feature attributes was keyed into the computer simultaneously as GPS-determined coordinates were automatically collected. The digital camera image allowed the team to cross check the accuracy of the attribute data collected. The GeoLink laser range finder option enabled the field team to automatically georeference and calculate distance and bearing offsets of inaccessible utility structures, such as electric vaults. It took less than 5 minutes to enter attributes related to any utility structure. The descriptive data of utility features were collected by using predefined "hot keys" on the keyboard for different attributes (for example, manhole, type, and so on).

Once the data collection process was complete and results were inspected, the data were exported from GeoLink's native storage format (.DAT, .PLG .MDB and .IDB files) to the target GIS or ARCView interchange format (.SHP, .SHX, and .DBF files). During the export of the data to ARC SHAPE file format, they were cleaned by setting the GeoLink Translate Filters with an average cluster outlier tolerance of 10 to collapse small unwanted polygons (for example, double- 
line roads, cul-de-sacs, and so on) and the weed filter of $10 \mathrm{~m}$ to remove unnecessary points. Setting the ARCView file extension to ERDAS Imagine Image support allowed the rectified images to be viewed as backdrops to the ARC SHAPE files. For example, electric vault ARC SHAPE files were superimposed on the ERDAS img file. Color and black-and-white ARCView graphic and tabular information was printed on a Canon BJ80 portable printer to supplement the verification process.

Each spatial base overlay was individually viewed in contrasting colors over the image and systematically inspected for proper fit (fig. 4). The ability to switch overlays and toggle to adjust the ARCView color display provided a quick visual check of the registration and any spatial inconsistencies. A random sampling was performed by systematically reviewing a vector display of the data set and image backdrop in subsections. Any feature that appeared to be either missing, altered, or unidentifiable in the image was marked for further inspection.
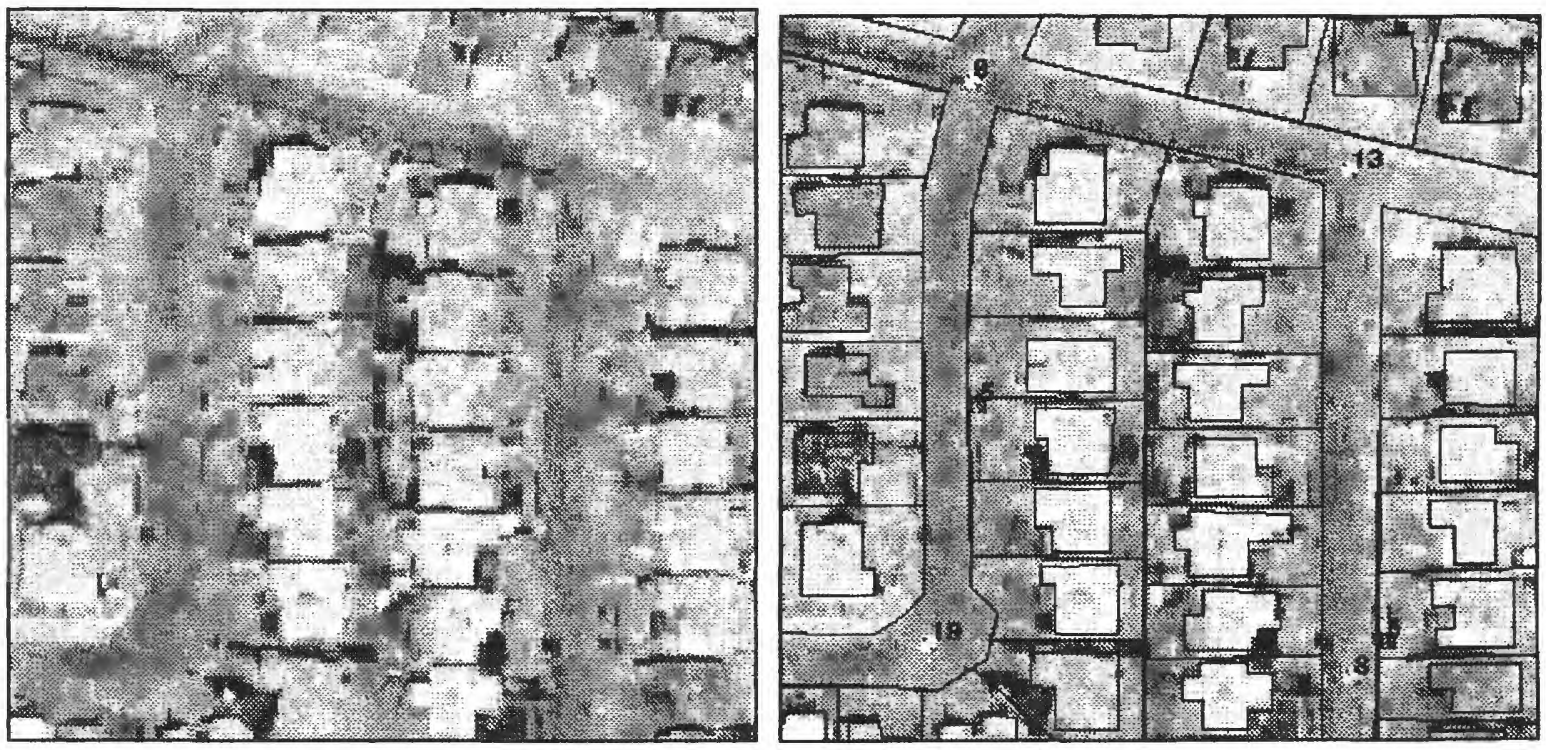

Figure 4. Comparison of 1-m GSD image at 1:1,500 scale of Oneida with and without database reference overlay showing location of manholes and electric vaults.

ANALYSIS

\section{Utility Structures}

By using the field-acquired GPS-based referenced data, the field team conducted a detectability test of the utility structures in the 1-m digital color images. On the computer screen, all relevant utility features that could be identified and interpreted were systematically plotted as vector overlays on the 1:9,000-scale image backdrop. Afterward, each newly plotted feature overlay 
was compared with its corresponding base reference data layer displayed in a second viewer. The ability to zoom, toggle, and combine overlays provided a quick indication of the features that were not captured. Any feature that appeared to be either missing or unidentifiable in the test was marked for further inspection.

\section{Accuracy Assessment}

The team checked the accuracy of the newly plotted feature layers of Oneida and Vado by comparing them to their corresponding layer from the base reference data (collected, annotated and edited in the field) and the $1-\mathrm{m}$ digital color image. This accuracy is defined as the proportion correctly identified and interpreted on the $1 \mathrm{~m}$ digital image when compared to the ground truths established from the base reference data gathered in the field (Sturdevant, 1981). An additional cross-check was made to verify that the entered data were correctly matched to the feature seen in the stored digital photograph.

The accuracy of the utility structures identified and interpreted in the Oneida and Vado IV images can be seen in tables 2 and 3, respectively. The high percentage totals for Vado IV reflect building and road features. The lack of or scarcity of public utilities in Vado IV is also evident; the only missing utility feature, a water valve, was observed on Tarin Road near the Ward Street intersection.

Table 2. Overlay matrix and summary statistics for Oneida $1 \mathrm{~m}$ pixel resolution image

Percentage of Feature:

Features: Bldgs Rds Ev Mh Wv Missing TOTAL Identified Interpreted

\begin{tabular}{|c|c|c|c|c|c|c|c|c|c|}
\hline Buildings & 164 & & & & & 2 & 166 & 98.8 & 98.8 \\
\hline Roads & & 10 & & & & 0 & 10 & 100 & 100 \\
\hline \multicolumn{10}{|l|}{ Utilities } \\
\hline \multicolumn{3}{|c|}{ Evaults (Ev) } & 0 & & & 19 & 19 & 0 & 0 \\
\hline \multicolumn{3}{|c|}{ Manholes (Mh) } & & 0 & & 17 & 17 & 0 & 0 \\
\hline \multicolumn{3}{|c|}{ Watervalve (Wv) } & & & 0 & 20 & 20 & 0 & 0 \\
\hline TOTAL & 164 & 10 & 0 & 0 & 0 & 58 & 232 & 75.0 & 75.0 \\
\hline
\end{tabular}


Table 3. Overlay matrix and summary statistics for Vado IV $1 \mathrm{~m}$ pixel resolution image

Percentage of Feature:

Features: Bldgs Rds Ev Mh Wv Missing TOTAL Identified Interpreted

Buildings

Roads

Utilities

Evaults (Ev)

Manholes (Mh)

Watervalve (Wv)
129

18

8

1

137

19

94.2

94.7

0

0

$0 \quad 0$

0

0

1

157

129

$18 \quad 0$

TOTAL

129

Because a higher resolution color image of the study area was not readily available, a sample 1:7,500-scale color photograph of the Ft. Dupont area, Washington, D.C., scanned at a 20-cm pixel resolution was used for comparison (figure 5). This $20-\mathrm{cm}$ sampled image was derived from
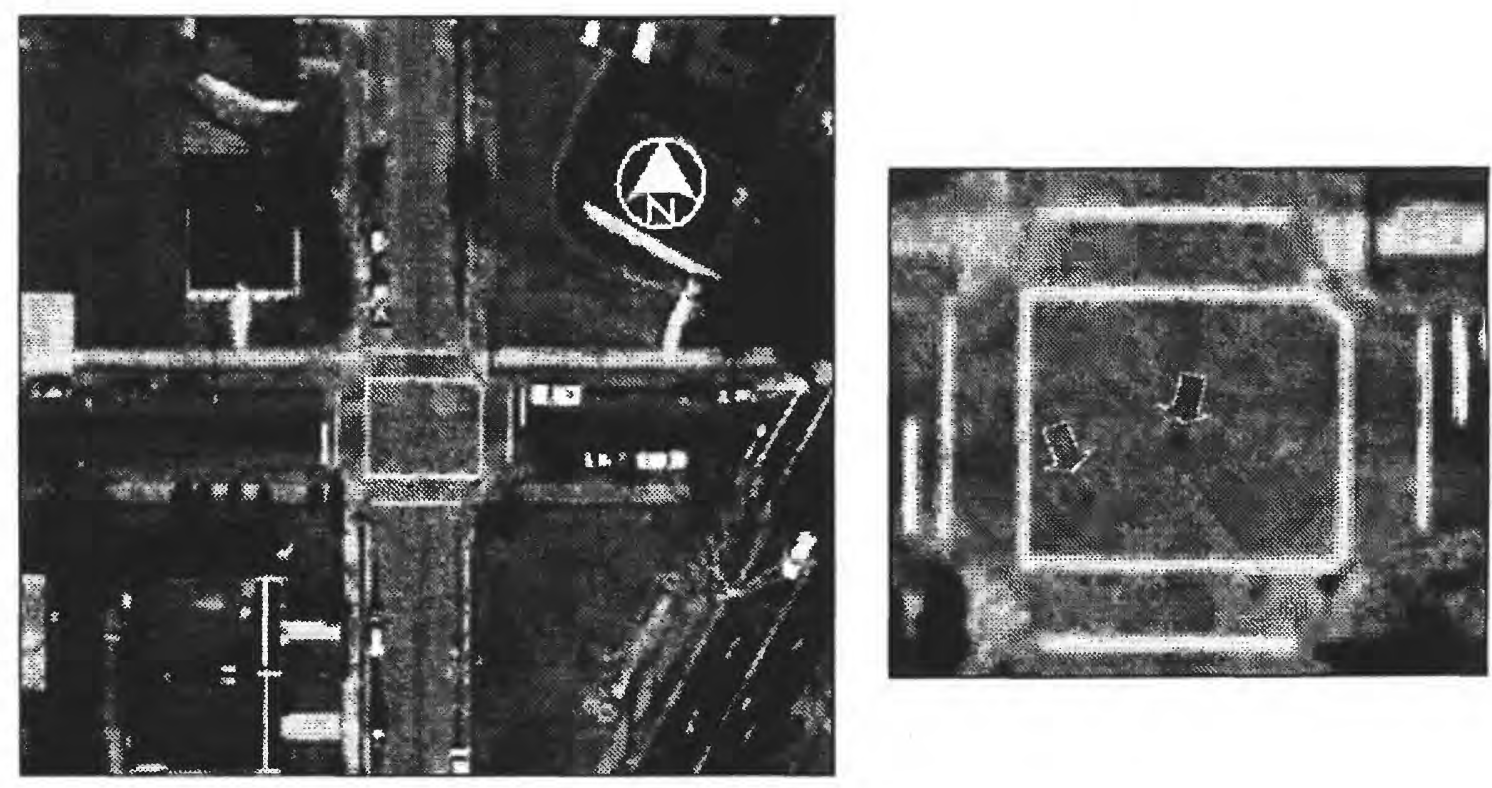

Figure 5. Example of manhole covers in 20-cm pixel resolution image, see arrows. 
aerial photographs flown for the National Capitol Planning Commission and was obtained from the National Park Service. In table 4, the summary statistics for 20 -cm imagery show the identification and interpretation significantly higher for the same utility features.

Table 4. Comparison statistics for sample $20 \mathrm{~cm}$ pixel resolution image

Percentage of Feature:

Features: Bldgs Rds Ev Mh Wv Missing TOTAL Identified Interpreted

\begin{tabular}{|c|c|c|c|c|c|c|c|c|}
\hline Buildings & & & & & 0 & 48 & 100 & 100 \\
\hline Roads & 5 & & & & 0 & 5 & 100 & 100 \\
\hline \multicolumn{9}{|l|}{ Utilities } \\
\hline Evaults (Ev) & & 9 & & & 1 & 10 & 90 & 90 \\
\hline Manholes (Mh) & & & 15 & & 2 & 17 & 88.2 & 88.2 \\
\hline Watervalves (Wv) & & & & 0 & 20 & 20 & 0 & 0 \\
\hline TOTAL & 5 & 9 & 15 & 0 & 23 & 100 & 77 & 77 \\
\hline
\end{tabular}

The low identification and interpretation results in tables 2 and 3 as compared with those of Table 4 demonstrate that $1 \mathrm{~m} \mathrm{GSD}$ imagery is unlikely to provide a viable alternative to $20-\mathrm{cm}$ pixel resolution for developing an infrastructure-type GIS. An evaluation with stereoimagery was not done here, but should show a significant improvement in identification and interpretation at $1-\mathrm{m}$ and $20-\mathrm{cm} \mathrm{GSD}$. However, the same trend is expected (that is, buildings and road features more recognizable than the utility structures).

\section{MONITORING CHANGES AND GROWTH}

Monitoring change and growth in colonia settlements is a natural extension of current research in developing landscape characteristics or "footprints" of these settlements from high-resolution digital imagery. The image mapping of physical surface change, trends, and growth pattern has traditionally been accomplished with coarse 20 - to 30 - $\mathrm{m}$ satellite sensors from four-band SPOT and six-band Landsat (thermal band not included) multispectral data, respectively. Because the equivalent multispectral satellite data at a high resolution were not available, contemporary source data and techniques were applied in this phase of the project. Further research is recommended when planned satellite systems with four-band, multispectral, 4-m GSD data become available.

\section{Satellite Image Preparation}

Satellite image preparation for the study consisted of processing four digital data sets in raster format from 1974, 1984, 1994, and 1996 Landsat scenes. Rectification and resampling were 
performed by locating the same 15 well-distributed photoidentified control points in each image and correlating their $\mathrm{x}$ and $\mathrm{y}$ positions to corresponding UTM coordinates. These points were then used in a least-square regression analysis to derive a first-order polynomial transformation of each image with less than a 1-pixel root-mean-square error. The MSS and TM data were resampled at a pixel size of $30 \mathrm{~m}$ (MSS at $60 \mathrm{~m}$ ) to a UTM projection, zone 13, NAD 83, and GRS 80. Following the registration and nearest neighbor resampling of the Landsat data, a highpass box filter was used to enhance the higher frequency spatial components of the image. The mapped area of each data set was then viewed in subsections to permit a quick, systematic inspection of the raster image display.

The team acquired supplementary source material in the form of sample spectra using groundtruthing field spectrometry techniques. A 350- to 2,500-nm full range of the Analytical Spectral Device (ASD) FieldSpec Spectrometer was used to analyze spectra groups in the project. The field team took measurements between $10 \mathrm{a} . \mathrm{m}$. and $3 \mathrm{p} . \mathrm{m}$. when the sun was at its highest above the horizon. Each target measurement was taken from a height of approximately 1-meter over the spectra, aiming vertically facing the sun. The instrument operator calibrated the spectrometer often to compensate for subtle changes in atmospheric humidity, sun angle, high-altitude haze, and dust that can introduce unwanted characteristics into the sample spectra.

\section{Change Analysis}

Several common visual and automated techniques used for identifying and interpreting physical change, trends, and growth pattern include (1) multidate visual comparison, (2) single-band change detection, (3) image differencing, (4) image regression, and (5) classification comparison. Multidate visual comparison uses monochromatic and stereophotos and airphoto interpretation techniques (shape, size, pattern, and so on) to identify changes over time. In single-band change detection, an image data set is created from multidate images, and various band color combinations are displayed to reflect variation in spectral response over time. Image differencing uses two registered satellite images, where radiance values from one date are subtracted from the corresponding location of the second date (Toll, 1980). The image-regression approach is a variation of the image-differencing technique whereby a least-squares transformation between dates is used to reduce adverse effects from differences in atmospheric conditions or sun angles. The fifth technique applies the classification of multispectral images for two dates then compares the classifications for nonurban to urban land cover change (referred to by Toll as postclassification comparison).

For the single-band change detection, a 30-m output pixel was selected to enable integration of the MSS and TM bands into a single-band data set. A single-band change detection image was created by comparing differences in the images' brightness values or digital numbers of TM band 7 (for the 1974 data, MSS band 4 was used). TM Band 7 (2.08-2.35 um) and MSS band 4 (0.8$1.1 \mathrm{um}$ ) were used because they enable the delineation of urban areas from nonurban areas and, in the case of TM band 7, penetrate haze in the atmosphere. TM bands 5 (1.55-1.75 um) and 7 have 
demonstrated operational value in the midinfrared for cultural delineation. However, because the two bands have high correlation, only one was used (Chavez, 1984).

In creating the change image, we assigned blue and green to the brightness values in the 1984 image and red to the brightness values in the 1996 image. The brightness values that have the same red, green, and blue intensities for both dates are shades of gray and will remain unchanged. The brightness values that were brighter in 1984 become shades of cyan because they are high in blue and green values and low in red. Conversely, the brightness values that were brighter in 1996 become shades of red because they are high in red and low in blue and green values. Therefore, cyan represents higher brightness or reflectance values in the 1984 display, and red represents higher reflectance values in the 1996 display. In the visual interpretation, intense shades of red and cyan, which result from the high amount of change between the 1984 and 1996 brightness values, indicate physical surface changes in the project area.

After the change scenes were created, showing changes between 1974 and 1984, image band and color combinations were generated to further analyze and classify the amounts and types of changes. Images of the three dates were generated using TM bands 7, 4, 2, and MSS 4, 3, 2, in red, green, and blue, respectively. This band and color combination delineates built-up land areas and differentiates vegetated and nonvegetated areas. In the 1974 image in figure 2, pink shows barren soil and white reveals nonvegetated areas or areas that have been cleared for construction. As anticipated, comparison of multitemporal images shows most changes taking place in the rural-urban fringes where most colonia settlements are located. The white areas in the 1974 and 1984 images have changed to bright green in the 1996 image, indicating a change from a cleared area to a built-up land area with vegetation. In the change image, such areas appear as bright cyan, which accurately denotes regions of large differences in spectral response between 1974, 1984, and 1996. On the basis of visual interpretation of the change images and the three Landsat scenes, it is possible to predict that the white areas in the 1996 image have been, or will soon be, Anderson's Level I Built-up Land areas, such as colonia settlements.

The potential of field spectrometry for the classification and mapping of surface change was not evaluated in this study. Because of the significance of spectral information, a separate investigation of its value to landscape change analysis should prove worthwhile.

\section{FINDINGS}

The detectability test results for the 1-m image revealed that most infrastructure features, with the exception of certain utility structures, could be observed at Anderson Levels I and II land use/land cover classification, and to some extent at a Level III classification (table 5). In general, when the images were displayed in black and white, they provided high detectability, but when they were displayed in color a greater level of interpretability was achieved. On the Vado IV image, waterrelated features, such as arroyos, drains, and irrigation canals, were easily detectable. Clearly recognizable were open fields, houses, highways (Interstate 10 and NM 227), and unpaved roads (there are no paved roads in Vado IV). Manmade features, such as level of unimproved roads 
(for example, ungraded, graded, or gravel), trails, and narrow footpaths, may require verification in the field. Small houses, mobile homes, discarded buses, ramshackle shacks, outhouse or privies, dismembered vehicles, and piles of rotting tires, trash and building materials, were easy to identify, but difficult to interpret (for example, houses of frame and brick construction). The identification of features such as levees or banks may require stereoimages or contour overlays.

Table 5. Detectability test results at $1-\mathrm{m}$ pixel resolution

Features

Roads and Trails

Utilities

Hydrography

Manmade

Transmission/Pipelines

\section{Class}

Levels 1, 2, 3

Levels 3, 4 in trees

Level 4

Levels 3, 4

Drains, arroyos

Small houses, lots, mobile homes

Transmission towers

Water pipelines

\section{Capture Results}

Easily recognizable in open areas, especially in color

Stereoimages essential

Paved/unpaved distinguishable in open areas; difficult to classify graded/gravel/ungraded w/o supplemental data

Difficult to impossible to capture w/o higher resolution data or field survey

Recognizable in open areas, better in color

Recognizable in open areas, better in color

Only if ground scar is visible, better in color

Only if above ground and scar visible, better in color

On the sample 20-cm GSD color image of Ft. Dupont, Washington, D.C., most utility structures were detectable and general identification was possible. However, manhole covers were more recognizable on concrete pavement than on asphalt, and smaller water valve covers were not detectable on either. Based on these detectability tests results, the detection and precise identification of Anderson Level IV utility structures will require images with less than 1-m GSD. 
Aerial photographs and satellite images are important to the feature identification process. However, processing such as digitizing and resampling can degrade the data, regardless of enhancement procedures. Further investigation into preserving the spatial and spectral fidelity after processing is recommended.

In the process of tiling or mosaicking, we found that each scanned aerial photograph has an associated accuracy that results in minor edge-matching problems. In an aerial photograph, tall objects appear to lean outward from the photograph's center. With orthophoto rectification, most of this distortion is correctable; however, large features near the photograph's edge that are dissected by the mosaic line may still appear distorted or displaced. For example, where a wide drain like Mesquite Drain runs between adjoining images, there may be relative displacement and mismatching. Also, both sides (for example, west and east sides) of a large building dissected by the mosaic line may be erroneously visible, as well as their shadows. Most of these displacements or distortions can be selectively smoothed during image processing, but they cannot always be positionally corrected. For high-resolution digital imagery, this particular problem may be reduced or eliminated in the near future, since orbital sensor systems generally have a narrowangle field-of-view, are near orthographic, and will basically eliminate many of the anomalies of the aerial camera (ISPRS Committee, 1984). However, for aerial photographs with better than 1$\mathrm{m}$ ground resolution, further research on displaced feature problems along the mosaic line is recommended.

The multidate satellite integrated data sets permitted image analysis and interpretation in several different parts of the visible to midinfrared spectrum at scales of up to 1:50,000. The single band change detection image provided better contrast and separation, making it easier to correctly identify physical surface alteration. Changes in manmade features were the most difficult to recognize from the satellite images and benefited the most from integration with newly created or existing spatial base data. Archived coarse or low-resolution multispectral satellite images alone may not be able to accurately determine the growth or change in colonia settlements. Adding another dimension to the potential of integration is the fusion of low-resolution multispectral data with archived source data from U.S. Government declassified high-resolution reconnaissance images from space (McDonald, 1995).

With the anticipated launch of a Space Imaging, Inc., satellite in December 1998, and other similar commercial launches over the next few years, satellites will provide multispectral sensor data with a pixel resolution of $4 \mathrm{~m}$ or better. These new sources of high-resolution multispectral data should increase the capabilities for generating landscape change information at local scales with greater geometric detail and accuracy. This project did not examine the potential of 4-m multispectral satellite data for temporal analysis. Because of the significance of temporal information for calibration, correction, and convergence of evidence for colonia growth trends, this topic deserves a complete study of its own.

The findings suggest that by using relatively large-scale (submeter GSD) and recently acquired digital images, scientists can identify economically depressed settlements like colonia settlements, 
as well as their level of infrastructure. This can be done at an 85 percent accuracy rate, or even higher if the digital images are supplemented or integrated with high-accuracy, georeferenced spatial field data.

The sample $20-\mathrm{cm}$ GSD color image used in this study demonstrates that higher resolution is necessary to identify and interpret the infrastructure characteristics in the form of public utility structures. The simulated $1-\mathrm{m}$ color image fell short in capturing most of these same characteristics. Public utility features, or their absence, are vital to the identification of colonia settlements and their levels of infrastructure. Because of the poor results, we can conclude that forthcoming 1-m GSD satellite imagery is unlikely to provide a viable alternative to low-altitude aerial photographs and high-resolution reconnaissance satellite images for the accurate (1) identification of colonia settlements, (2) assessment of settlement patterns, population estimates, housing, and living conditions, and (3) development of a prototype data set.

\section{CONCLUSION}

The integration of better than 1-m GSD images and high-accuracy, georeferenced, field-collected spatial data in an infrastructure GIS database can provide a highly flexible tool for documenting the level of public utilities in colonia settlements. Because of the absence of real satellite imagery with 1-m panchromatic and 4-m multispectral GSD, the digitized aerial photographic data were used instead, and only simulated the pixel GSD. It is important to keep in mind the limitations of current and future satellite image integration with spatial base data, and to balance the criteria for its use against practical considerations of designing a colonia settlement GIS database. Pixel size, ground control, topography, and accuracy of the DEM govern the factors determining suitability of digital images for a given application. Digital images at 1-meter GSD from commercial satellites and, in most cases, commercially available coarse DEM's will not be suitable for largescale projects requiring pixel footprints of utility structures with submeter positional accuracy (table 6).

Another factor to consider is that, unless the essential topographic data are digitized or generated from planned orbital space-imaging systems capable of mapping in flat and rough terrain, orbital sensor data available for a colonia settlement GIS database may be limited to digital planimetric base data. Studies of the use of satellite data for surveying and mapping indicate that $5-\mathrm{m}$ contours can be derived from $2.5-\mathrm{m}$ pixel systems suitable to produce a 1:25,000-scale line map where a satisfactory base-to-height ratio and adequate geometric constraints are imposed (Frederick J. Doyle, 1984, unpub. data). Theoretically, SPOT 3 and planned orbital systems identified in the PE\&RS Journal (Jensen, 1995), such as SpaceImaging, can be used for topographic mapping but only after extensive image processing to correct the stereomodel (A. Colvocoresses, oral commun. August 14, 1995). The problem lies within the movement of the sensor during the pass to collect the fore and aft images needed for stereopairs that "disrupts continuity and complicates the geometric solution of the stereomodel" (Fester, 1995). Possible exceptions are EarthWatch and SPOT 5 systems. SPOT 5 stereoscopic configuration is similar in design to the USGS's MAPSAT (Colvocoresses, 1982). Both EarthWatch and SPOT 5 systems 
are designed to limit the movement of the sensor and to reduce the discontinuity of orbit, thus permitting straightforward geometric solution of the stereomodel. These two exceptions will provide continuous real time data and should meet most of the parameters for an orbital mapping system recommended by the ISPRS Committee, Commission IV Report (1984).

Table 6. Detectability requirements as they relate to developing infrastructure GIS through remote sensing (values are GSD or pixel equivalents in metric units)

Feature

Roads \& Trails

Catch Basin

Electric Vault

Fire Hydrant

Gas Valve

Light (private)

Light (street)

Manhole (electric)

Manhole (gas)

Manhole (storm sewer)

Manhole (waste water)

Manhole (telephone)

Pole (telegraph)

Pole (utility)

Water Valve

Drains/ditches

Houses/mobile homes
Detection

$9 \mathrm{~m}$

$90 \mathrm{~cm}$

$90 \mathrm{~cm}$

$30 \mathrm{~cm}$

$15 \mathrm{~cm}$

$15 \mathrm{~cm}$

$15 \mathrm{~cm}$

$60 \mathrm{~cm}$

$60 \mathrm{~cm}$

$60 \mathrm{~cm}$

$60 \mathrm{~cm}$

$60 \mathrm{~cm}$

$30 \mathrm{~cm}$

$30 \mathrm{~cm}$

$15 \mathrm{~cm}$

$4 \mathrm{~m}$

$2 \mathrm{~m}$
General I.D

$6 \mathrm{~m}$

$50 \mathrm{~cm}$

$50 \mathrm{~cm}$

$15 \mathrm{~cm}$

$7 \mathrm{~cm}$

$7 \mathrm{~cm}$

$7 \mathrm{~cm}$

$20 \mathrm{~cm}$

$20 \mathrm{~cm}$

$20 \mathrm{~cm}$

$20 \mathrm{~cm}$

$20 \mathrm{~cm}$

$15 \mathrm{~cm}$

$15 \mathrm{~cm}$

$7 \mathrm{~cm}$

$2 \mathrm{~m}$

$1 \mathrm{~m}$
Precise I.D. Attribute I.D.

$2 \mathrm{~m}$

$60 \mathrm{~cm}$

$25 \mathrm{~cm}$

$15 \mathrm{~cm}$

$25 \mathrm{~cm}$

$15 \mathrm{~cm}$

$7 \mathrm{~cm}$

$3 \mathrm{~cm}$

$3 \mathrm{~cm}$

$1 \mathrm{~cm}$

$3 \mathrm{~cm}$

$1 \mathrm{~cm}$

$3 \mathrm{~cm}$

$1 \mathrm{~cm}$

$5 \mathrm{~cm}$

$10 \mathrm{~cm}$

$5 \mathrm{~cm}$

$10 \mathrm{~cm}$

$5 \mathrm{~cm}$

$10 \mathrm{~cm}$

$10 \mathrm{~cm}$

$5 \mathrm{~cm}$

$10 \mathrm{~cm}$

$5 \mathrm{~cm}$

$7 \mathrm{~cm}$

$3 \mathrm{~cm}$

$7 \mathrm{~cm}$

$3 \mathrm{~cm}$

$3 \mathrm{~cm}$

$1 \mathrm{~cm}$

$1 \mathrm{~m}$

$50 \mathrm{~cm}$

$50 \mathrm{~cm}$

$25 \mathrm{~cm}$

The anticipated supply of commercially produced 1- to 4-m GSD satellite data will increase the data available to Federal agency users, but where much finer detail is needed, quality source data will have to come from commercially flown low-altitude aerial photographs or higher resolution Government satellite images. These higher resolution sources of digital images will be essential to HUD for determining the level of infrastructure of colonia settlements through remote sensing. 


\section{ACKNOWLEDGMENTS}

The author would like to thank Larry Hothem, USGS, Michael E. Slifer, USGS Water Resource Division, Las Cruces Subdistrict Office, and Judy Price, Dona Ana County Planning Office, for their support and contributions to this project. The U.S. Department of Housing and Urban Development provided part of the funding for this project.

\section{REFERENCES}

Albuquerque Journal, 1996, New Mexico Places, Albuquerque Journal, Inc., Albuquerque, NM, June 16, 1996.

Anderson, J.R., Hardy, E.E., Roach, J.T., and Witmer, R.E., 1976, "A land use and land cover classification system for use with remote sensor data:" U.S. Geological Survey Professional Paper 964, 28 pp.

Chavez, Pat Jr., and Bowell, J. A., 1984, "Image processing techniques for thematic mapper data:" Proceedings of the Meeting of American Society of Photogrammetry and Remote Sensing, Washington, D.C., p. 728-752.

Colvocoresses, A.P., 1982, "An automated mapping satellite system (MAPSAT):"

Photogrammetric Engineering \& Remote Sensing, Vol. 48, No. 10, pp. 1585-1591.

Doyle, F.J., 1984, ISPRS Past President's Presentation to Symposium, "Use of satellite data for surveying and mapping:" Symposium on Present Status of Modern Surveying Federation International des Geometres, Tokyo, Japan.

Ehlers, M., 1993, Integration of GIS, remote sensing, photogrammetry and cartography: The geoinformatics approach: GeoInformations-Systeme (GIS) 6(5), pp. 18-23.

Fester, W., 1995, "Worldview merger seen as harbinger for field:" Space News, Vol. 6, No. 4, January 30 - February 5, p4, col. 1 .

Frenzel, P.F., and Kaehler, C.A., 1990, GeoHydrology and simulation of ground-water flow in the Mesilla Basin, Dona Ana County, New Mexico and El Paso County, Texas: USGS Open-File Report 88-305, p. 9.

Holz, RK., and Davies, C. S., 1992, Remote sensing techniques for population estimation of colonias in the Lower Rio Grande Valley of Texas: Geocarto International (2), pp. 21-32.

International Society for Photogrammetry and Remote Sensing Committee, 1984, Report of the Committee for Acquisition and Processing of Space Data for Mapping Purposes of the Working Group IV/3. 
Jensen, J.R., 1995, ASPRS President's Inaugural Address, "Provide leadership in the definition of National Spatial Data Standards and characteristics of public remote sensor system:" Table 2.

Land Data Satellites that may be Launched from 1995 through 2004, Photogrammetric Engineering \& Remote Sensing, Vol. 61, No. 7, pp. 839-840

Lyndon B. Johnson School of Public Affairs, 1996, Preliminary report on colonia housing and infrastructure--current population and housing characteristics, future growth, and housing, water and wastewater needs: Policy Research Project on Colonia Housing and Infrastructure.

McDonald, R.A., 1995, "Open the cold war sky to the public--declassifying satellite reconnaissance imagery:" Photogrammetric Engineering \& Remote Sensing, Vol. 61, No. 4, pp. 385-390.

Sanchez, R.D., and Hothem, Larry, 1998, Field mapping using high-resolution digital images and global positioning system and geographic information system data: Proceedings of the Meeting of the American Society of Photogrammetry and Remote Sensing, Tampa Bay, Florida, March 1998, CD-ROM.

Seitz, Patrick, 1995, "Lockheed eyes market opportunities for maps:" Space News, Vol. 6, No. 4., January 30 - February 5, p. 4, col. 1.

Sturdevant, J.A., 1981, "Assessing accuracy of digital land use and terrain data:" Proceeding of the Meeting of American Society of Photogrammetry and Remote Sensing, San Francisco, California, p. 101-112.

Sullivan, C.A., 1994, "Colonias and migrant housing in Dona Ana County:" Report by the Border Research Institute, Las Cruces, New Mexico.

Toll, D.L., Royal, J.A., and Davis, J.B., 1980, Urban area update procedures using Landsat data: Proceeding of the Meeting of American Society of Photogrammetry and Remote Sensing, October $1980,12 \mathrm{p}$. 